\title{
Training-Domain-Process-Evaluation Framework for Web-Based Industry-oriented Mini-Project
}

\author{
Pallam Ravi $^{1}$, A.Obulesh ${ }^{2}$, A.Mallikarjuna Reddy ${ }^{3}$ \\ ${ }^{1,2,3}$ Computer Science Engineering, Anurag Group of Institutions, Hyderabad \\ ${ }^{1}$ pallamravicse@cvsr.ac.in \\ 2obuleshcse@cvsr.ac.in \\ ${ }^{3}$ mallikarjunreddycse@cvsr.ac.in
}

\begin{abstract}
Computer science and information Technology engineering graduates have credits for industry-oriented mini-Project, student select one problem that solves using computer science Technology, the web technologies is one of the significant technology, primary students work on web technology, students face any problem while developing industry-oriented mini-Project, like in technologies usage, understanding problem domain, development process, timely complete project within time and complete functionalities, in this paper we propose a Framework called Training-Domain-Process-Evaluation (TDPE) to address problems which are students faced in technology learning ,understanding problem in domain ,development process and this methodology gives guidelines to industry-oriented mini-Project evaluation for mentors, we use this Framework for a class with 66 students, by use of this Framework increased student technology skill level, student involved in teamwork and increase student project completion within time and prespecified functionalities
\end{abstract}

Keywords: industry-oriented mini-Project, Web technologies, Domain problems, and Framework

\section{Introduction:}

Engineering is creating and developing the products using scientific rules, as computer science and information technologies also develop the software products, for producing human resources in fields of computer science and information technologies, technical universities/colleges in India are offers computer science Engineering (CSE) and information technologies(IT) programs in gradational level Bachelor Technology(B.Tech) or Bachelor Engineering(BE).

Technical Universities/colleges awarding B.Tech/BE degree to students, those are got minimum academic credits, the student got credits by passing the courses in that program, the mini-projects is one of the courses which is core course, students are compulsory to pass in the industry-oriented mini-Project course[10][11].

The main objective of the industry-oriented mini-Project course is that students got to explore technology, software development process, and work with real-time problems, work with team and student explore with industry practices. The general practices in Universities/colleges are form assign projects to project teams or individual students, student trained in technologies by course offered by programs or external training institutions, student face problem in web projects problem understanding, project required technologies and software development process and complete the project within time and complete functionalities, a guide assigned to each projects, for continuous assessment the project no tool $\mathrm{s}$ is available

Web application developed in various methodologies, UML-based Web Engineering (UWE)[1], Navigational Development Techniques (NDT) [2], and Web Requirement Engineering[3]. Many authors contributed to improving the quality of web project GORE techniques[4], expressive power of UML-based web engineering[5], Weboriented Software Technology[6], CASE-Tools used for web applications[7], Client needs and the design process in web projects[8]

We propose a framework call Training-Domain-ProcessEvaluation(TDPE), which have guidelines for technology training, how to understand a problem in domain space, development step by step process and how to a guide continuous evaluate the project

In this paper organized as in section 2 -Domain-ProcessEvaluation(TDPE) framework introduction, section 3 technology training guidelines, understanding a problem in section 4 , and project implement step by step procedure in section 5 and section 6 continuous evaluation guidelines for guide and section 7 impact of Domain-ProcessEvaluation(TDPE) framework. 


\section{Training-Domain-Process-Evaluation (TDPE) Introduction}

The TDPE framework consists of four main components namely training, process, domain, and evaluation, it gives technology training guidelines, understanding problem in Domains, and project implement step by step procedure inprocess and In evaluation continuous evaluation guidelines for project guides, the central is evaluation component which role is to make other components achieve oral goal of student project, which shows in fig 1 .

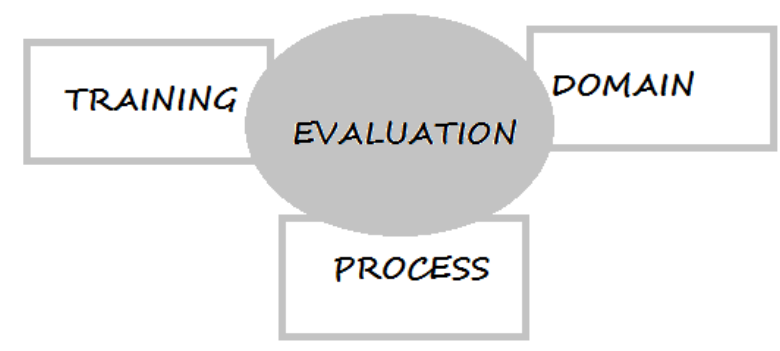

Fig 1: Block diagram of Training-Domain-ProcessEvaluation (TDPE)

\section{Training:}

To start industry-oriented mini-Project ,the student have technology skills for carried out it, it is main component the TDPE framework, in web projects context, student acquired skills about web technologies[12][13], the web projects is collection of interlinked web documents, web document has web elements, the web document have data which we are displayed on it, structure where it displays, presentation how it was displayed

The framework guideline for training:

1.Page Layouts Techniques

2.Presentation Techniques(CSS)

3. Data Representation(Multi-Language Support)

4.Data Validation. Responsive To User Interactions (Javascript)

5. Front-End Frameworks

6. Responsive Web Design

7. Progressive Web Design

8. Server-Side Scripting

9. Database Design

10. Session Management

11.Database Connectivity with Server-Side Scripting

12.Web Application Taxmony (CURD. Pagination...Ects)

13.Database change Compatibility

14. Style change Compatibility

\section{Domain:}

The second essential component in TDPE framework is domain. It's dealing with problem understanding. student project belongs to one domain(hospital.education.insurance . etc.).student should understand the domain terminology .constrains and process The framework guideline for Domain:

1.Identify The User of the Software(Actors)

2.Identify The Functionality of each actor (Use case)

3.Structure of the Objects involved in that Domain

4.Identify how many ways you can provide functionalities to actors and Its Sequence of Action(Scenarios)

5.Different State Of Each Object In Domain

6.What Is Business Flow Of That Domain(Work Flows)

7.Understand Vocabulary In Domain

\section{Process:}

The third component in the Framework is a process which deals with how student start the project works step by step.the student has to complete training and clearly understanding the problem in the domain the start the project

The framework guideline for the process:

1.Design User Interfaces For Each functionality Including All Scenarios

2. Design Database For Project

3.Insert Sample Data in Database

4.Implement User Authentication Functionalities

5.Identify Dynamic Data in All Webpages

6.Develop Functionalities One by One For Each Acterwise

7.Develop Admin Functionalities

8.Implement User Privilege

9. Implement Web Security

10. Hosting Web Application

\section{Evaluation}

The last component in the Framework was evaluation .in this, the project guide plays a complete role. It assesses how the student teams work to words complete the projects within time and implement all functionalities.

The framework guideline for Evaluation:

1.Form The Project Teams With 3 Students. Using Snake Order

2.Finalize Projects Title within Two Weeks

3.Evaluate The Domain Understand in Context with a Project Title

4.Finalize The Actors And Its Functionalities

5.User Privilege Access Implementation

6.Make Web Application In Live(Hosting)

\section{Impact Of Domain-Process-Evaluation(TDPE) Frame Work}

This Framework implemented in our college for 66 students. We formed the teams with 3 students in each team(snake order method).the implementation of Framework as follows

Training: first we conduct technology Training on clientside technologies (HTML, CSS, JavaScript, ..etc.), and 
Frameworks .finalize student project titles of each team . and training on server-side scripting (PHP)

Domain: Explain how to understand the problem in the selected domain follow all guidelines in domain component in the Framework

Process: Each team Design user interfaces for each function, including all scenarios. Design database for project, and insert sample data in the database, implement user authentication functionalities then identify dynamic data in all web pages. Take guide suggestion to develop functionalities one by one for each actor wise .for each functionality develops admin functionalities and follows all guidelines in-process component in Framework.

Once teams are developing all functionalities, the implemented user privatizations and made some web security precautions. finally, all projects hosted at our serverhttp://anuragweb.club

We measure the impact of the Framework with the following parameters

1. Student Technology Skill Level

2.Projects Completed In Time With All Functionalities 3. Student Work With Team

\begin{tabular}{|c|c|c|c|}
\hline \multicolumn{4}{|c|}{ Project Title: ApotheCary } \\
\hline \multicolumn{2}{|c|}{ Domain: Medicine } & \multicolumn{2}{|c|}{ Technology: PHP } \\
\hline \multicolumn{2}{|c|}{ Team Details: } & Team Guide & Team No \\
\hline Name & Roll No & \multirow{4}{*}{ Pallam Ravi } & \multirow{4}{*}{6} \\
\hline R.Sanjana & 15H61A0538 & & \\
\hline Pranay & 15H61А0539 & & \\
\hline J.Reena & 15H61A0518 & & \\
\hline
\end{tabular}

\begin{tabular}{|c|c|c|c|}
\hline Actor & & Use Cases & Status \\
\hline \multirow{4}{*}{ Chemists } & 1 & $\begin{array}{l}\text { Add/manage products in the online } \\
\text { inventory system. }\end{array}$ & 2 \\
\hline & 2 & Take the orders from users. & 2 \\
\hline & 3 & $\begin{array}{l}\text { Suggest alternate medicines if ordered } \\
\text { medicine's gone out of stock. }\end{array}$ & 2 \\
\hline & 4 & Give health tips to the user. & 2 \\
\hline \multirow{7}{*}{ Customers } & 5 & Search for essential medicine. & 2 \\
\hline & 6 & Compare cost at different stores. & \\
\hline & 7 & Place the order. & 2 \\
\hline & 8 & $\begin{array}{l}\text { Check availability of medicines in nearby } \\
\text { stores. }\end{array}$ & 2 \\
\hline & 9 & $\begin{array}{l}\text { Checks alternative medicine with the } \\
\text { same composition. }\end{array}$ & 2 \\
\hline & 10 & Track the order. & 2 \\
\hline & 11 & Gives feedback/ratings & 2 \\
\hline \multirow{4}{*}{ Super User } & 12 & Generate credentials for each chemist. & 2 \\
\hline & 13 & Suggests nearby stores to the user. & 2 \\
\hline & 14 & Manages discounts on orders. & 2 \\
\hline & 15 & $\begin{array}{l}\text { Suggests tips to chemists based on users } \\
\text { feedback. }\end{array}$ & 2 \\
\hline
\end{tabular}

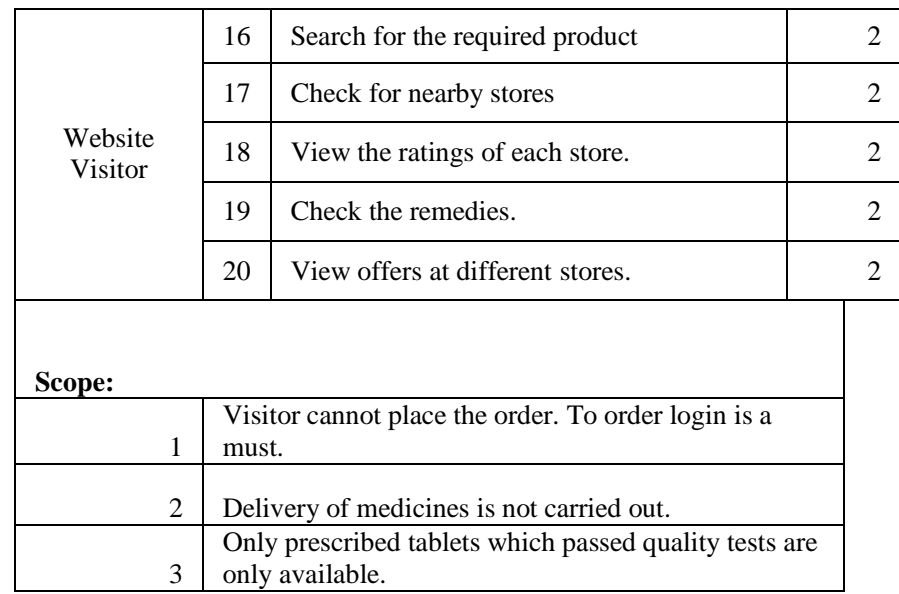

Fig 2: The mentor sample evaluation sheet

\section{Technical Skills}

$\square$ TDPE $\square$ OTH

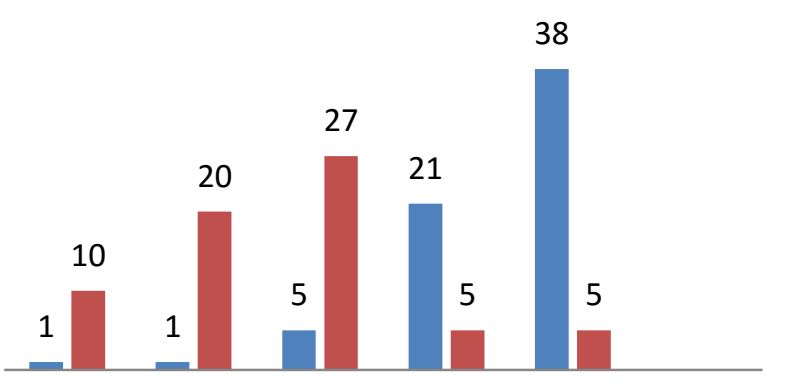

level-1 level-2 level-3 level-4 level-5

Fig 3: Student Technical skills levels with TDPE and Other (OTH)

\section{TDPE}

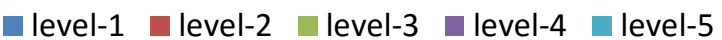

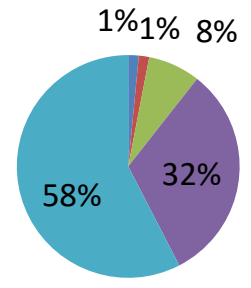

Fig 4: Student Technical skills levels with TDPE 


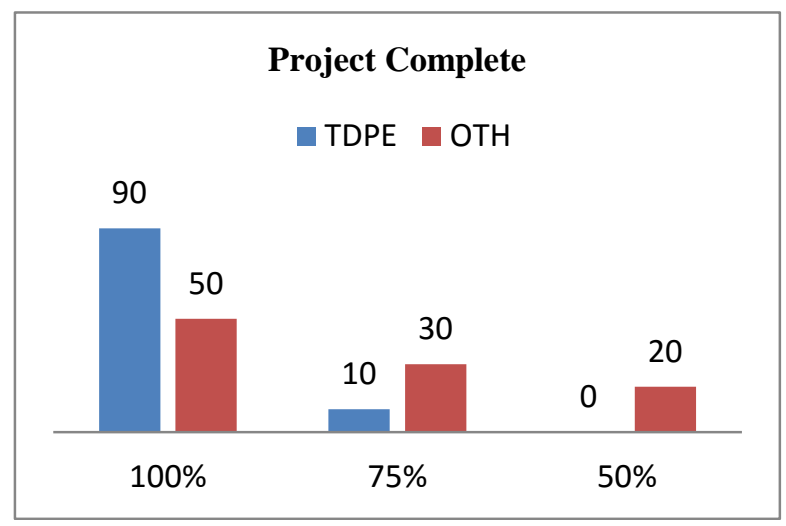

Fig 5: Student Completed with TDPE and Other (OTH)

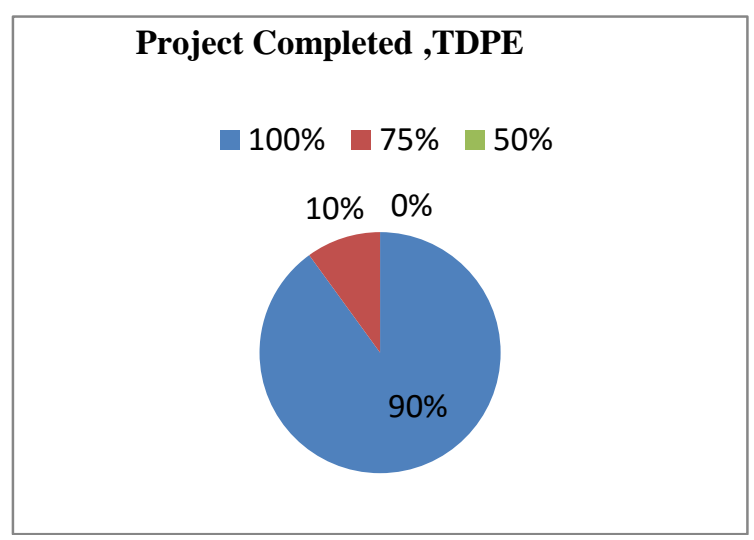

Fig 6: Student Completed with TDPE

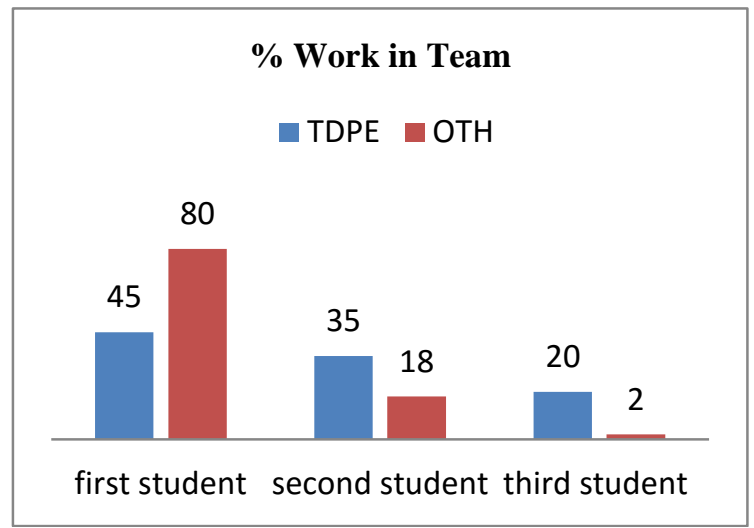

Fig: Student work in Team with TDPE and Other (OTH)

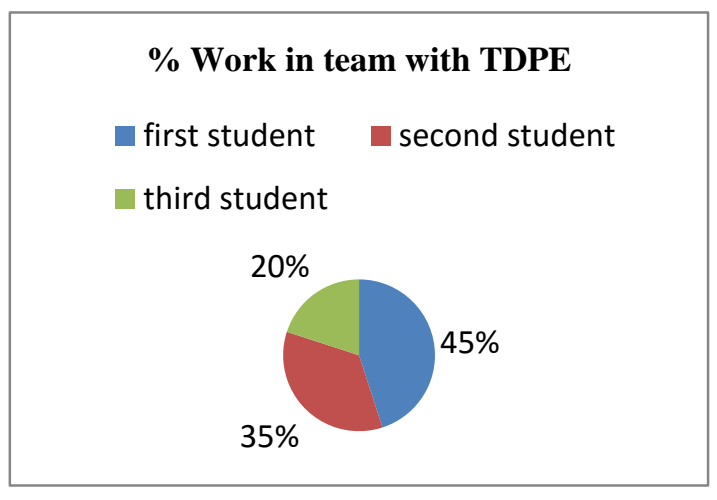

Fig: Student Work in Team with TDPE

To evaluate Student skills in web technology, The knowledge categories in 5 level, It evaluated by conduct online exam for 100 marks, which consist of all level ( boom taxonomy), the exam has 20 questions in level -1 for 20 marks, 10 questions in level-2for 20 marks. 7 questions in level -3 for 20 marks(only one question with two marks), 5 questions in level -4 for 20 marks and 4 questions in level -5 for 20 marks.

To categories of student knowledge based on marks got in the exam, below 20 marks students treat as level-1, between 20,40 marks students treat as level2,40,60 students treat as level-3, between 60,80 marks students treat as level-4,between 80,100 marks students treat as level-5.

The training is task-based, student involve in implementing real-time functionalities in their projects and involve all the team members in project work due to this student knowledge level increased it shows in 'Fig 3,in Fig 4 percentage of student knowledge in different level in TDPE framework

We conduct the viva-voce on their projects with external examiner, examiner evaluate based functionalities implementation and, student role in team .by use of our Framework, the project mentor is continuous monitor the project, so all member in team involved and completed all pre-defined functionalities monitor, project completion in time increased show in Fig5, the project completion categories in three, one $100 \%$ means project completed above $90 \%$ of predefined functionalities implemented, the second categories 75\% means project completed above $60 \%$ and below $90 \%$ of pre-defined functionalities implemented, the third categories is $50 \%$ means project completed below $60 \%$ of pre-defined functionalities implemented, in Fig 6 percentage of student projects completed with three categories, student work in team increase shows in Fig 7, in Fig 8 percentage of student work in team.

\section{Conclusion}


The TDPE framework has guidelines for training. Understanding the problem in domain .process to carryout the project and continuous evaluation for student works. Our experiment reveals that it increate student technical skills levels. involve in the team and complete the project within time and pre-specified functionalities

This Framework also adopted for other engineering disciplines with a change in training guidelines .its depended on engineering disciplines which apply this Framework

\section{References}

1. Conallen. J. (1999). Building web applications with UML. New York: Addison-Wesley

2. Escalona. M. J..\& Aragón. G. (2008). NDT. A model-driven approach for web requirements. IEEE Transactions on software engineering. 34(3). 377-390.

3. Escalona. M. J..\& Koch. N. (2004). Requirements engineering for web applications - A comparative study. Journal of Web Engineering. 2(3). 193-212

4. Chawla. S.. Srivastava. S..\& Bedi. P. (2017). Improving the quality of web applications with web specific goal

5. onKoch. N..\& Kraus. A. (2002. June). The expressive power of uml-based web engineering. In Second

6. International Workshop on Web-oriented Software Technology (IWWOST02) (Vol. 16). CYTED software engineering. 34(3). 377-390.

7. Fowler. L.. Armarego. J..\& Allen. M. (2001). CASE- Tools: Constructivism and its application to learning and usability of software engineering tools. Computer Science Education. 11(3). 261-272.

8. Lowe. D. \& Eklund. J. (2002). Client needs and the design process in web projects. Journal of Web Engineering. 1(1). 23-26

9. KD Schewe. B Thalheim (2019) Design and Development of Web Information Systems.springer

10. Frank. M.. Lavy. I. \& Elata. D. (2003). Implementing the project-based learning approach in an academic engineering course. International Journal of Technology and Design Education. 13. 273-288.
11. Green. A.M. (1998). Project-based learning: Moving students toward meaningful learning. In L. P. Steffe \& J. Gale. (Eds.). Constructivism in Education. New Jersey Lawrence Erlbaum Associates.

12. Murugesan. S..\& Ginige. A. (2001): Web engineering: An introduction. IEEE Multimedia. 8(1). 14-18

13. Whitehead. E. J. (2002). A proposed curriculum for a masters in web engineering. Journal of Web Engineering. 1(1). 18-22. 